\title{
Is the Use of $\beta$-Blockers in COPD Still an Unresolved Dilemma?
}

\author{
Antonio Foresi ${ }^{\mathrm{a}}$ Giampaolo Cavigioli $^{\mathrm{a}}$ Giordano Signorelli $^{\mathrm{b}}$ \\ Maria Beatrice Pozzonic ${ }^{c}$ Dario Olivieri ${ }^{d}$ \\ Divisions of a Respiratory Medicine and ${ }^{b}$ Cardiology, A.O. Istituti Clinici di Perfezionamento, Sesto San \\ Giovanni Hospital, Sesto San Giovanni, ' Division of Cardiology Rehabilitation, A.O. Istituti Clinici di \\ Perfezionamento, CTO Hospital, Milan, and ${ }^{\mathrm{d}}$ Chest Clinic, Rasori Hospital, Parma University, Parma, Italy
}

\section{Key Words}

Adrenergic receptors $\cdot \beta$-Blockers $\cdot$ Chronic obstructive pulmonary disease $\cdot$ Cardiovascular diseases $\cdot$ Heart failure

\begin{abstract}
$\beta$-Blockers are competitive antagonists at $\beta$-adrenergic receptors $(\beta-A R)$ and are a life-saving form of treatment in different cardiovascular diseases (CVD). Despite current guidelines supporting the use of selective $\beta_{1}$-blockers in patients with CVD and especially in heart failure (HF), they are still largely underused, mostly as a consequence of the presence of chronic obstructive pulmonary disease (COPD). In primary care, prevalence of COPD in patients with HF is approximately $25 \%$, and it will rise in the next years. In the general population, only $20 \%$ of COPD patients with HF are treated with $\beta$-blockers. $\beta$-Blockers may result in pulmonary adverse effects that are relevant to COPD patients. Bronchoconstriction may be the consequence of: absence of cardioselectivity; loss of cardioselectivity at high doses, and unopposed stimulation of cholinergic muscarinic $\mathrm{M}_{2}$ receptors. The concern of inducing bronchospasm is the more likely explanation of a poor prescription of $\beta$-blockers in patients with CVD also suffering from COPD. However, under carefully controlled conditions, which include close monitoring of lung function and appropriate selection of the drug and titration
\end{abstract}

of the dose on a case-by-case basis, selective $\beta_{1}$-blockers can be safely administered to most patients with COPD. Pneumologists and cardiologists should develop a detailed and standardized protocol to guide the use of selective $\beta_{1}$-blockers in everyday practice, which could significantly reduce the physicians' mistrust of $\beta$-blockers in COPD patients.

Copyright $\odot 2010$ S. Karger AG, Basel

\section{Introduction}

Chronic obstructive pulmonary disease (COPD) is a very common smoking-related disease, characterized by persistent airway obstruction and increasing morbidity and mortality worldwide [1]. Patients with COPD also have coexisting cardiovascular co-morbidities [2] associated with COPD exposure to smoke and chronic inflammation, i.e. chronic heart failure (CHF), coronary artery disease (CAD) and hypertension.

Previous articles in this series: 1 . Suissa S: Co-morbidity in COPD: The effects of cardiovascular drug therapies. Respiration 2010;80:3-7. 2. Barnes PJ: Inhaled corticosteroids in COPD: A controversy. Respiration 2010;80:89-95.

\section{KARGER}

Fax +41613061234 E-Mail karger@karger.ch www.karger.com
(ㄷ) 2010 S. Karger AG, Basel 0025-7931/10/0803-0177\$26.00/0

Accessible online at:

www.karger.com/res
Antonio Foresi, MD

Division of Respiratory Medicine, Sesto San Giovanni Hospital

A.O. Istituti Clinici di Perfezionamento

Viale Matteotti 83, IT-20099 Sesto San Giovanni (Italy)

Tel. +39 0226257 356, Fax +390226257 636, E-Mail antonio.foresi@icp.mi.it 
Cardiovascular diseases (CVD) are often the first or second cause of death in COPD patients, regardless of the severity of airway disease. Approximately one third of patients with COPD die of CVD [3-5], and COPD patients are at increased risk of death and hospitalization for CVD [6]. In patients hospitalized for heart failure (HF), COPD worsens the prognosis [7].

COPD prevalence in patients with CHF ranges from 23 to $33 \%$ [8-11], whereas about $25 \%$ of elderly patients with COPD have unrecognized CHF [6]. In the community, prevalence as well as incidence have increased in the last decade, both in men and women [11], and approximately two thirds of the patients with HF and COPD are current or previous smokers [11]. Retrospective analysis of health care data shows that the odds ratio of prevalence of congestive HF in COPD is 3.8 times that of similar agematched non-COPD patients [6]. Elderly patients with clinical or functional diagnosis of COPD with concurrent, mostly left-sided, early-stage HF (in the general population half of the patients with $\mathrm{CHF}$ are aged $>75$ years) [12] had twice the risk of dying compared with COPD patients without $\mathrm{HF}$ [13]. COPD patients more frequently die of CVD [4], mainly as a consequence of CHF [14]. It should be noted that the 5-year survival rate in patients with COPD and HF is approximately $70-80 \%$ [13], suggesting that adequate treatment of HF changes the prognosis in COPD patients remarkably $[8,13]$. However, from a therapeutic standpoint, the coexistence of COPD and CHF complicates HF treatment and is often responsible for suboptimal pharmacological intervention. Moreover, the higher mortality of patients with concomitant $\mathrm{CHF}$ and COPD has been linked to an under-use of recommended pharmacological treatment, such as $\beta$-blockers [15].

Indeed, the coexistence of COPD and CHF exposes patients to a double jeopardy. From a diagnostic point of view, CHF can remain misdiagnosed in COPD because the symptoms are similar and the increasing volumes associated with COPD hamper auscultation of cardiac tones. Furthermore, the acoustic window is frequently poor in COPD patients, thereby impeding evaluation of cardiac function by Doppler echocardiography [16]. The diagnosis and treatment of coexistent COPD and CHF is even more challenging, especially in the elderly, due either to their partial inability to perform pulmonary function tests and/or decreased accessibility of health resources. Indeed, the morbidity of patients with COPD and $\mathrm{CHF}$ will rise in the next years due to prolonged life expectancy, as both conditions become increasingly more prevalent with age. As the adjusted mortality rate for
COPD still rises and the mortality of patients with CHF remains stable, the importance of treating both conditions optimally has to be stressed.

CAD has been reported in 10 [17] to $20 \%$ of patients with COPD [18], whereas the prevalence of COPD in adults with systemic hypertension is similar to that in the general population (approximately 30\%) [19].

The reason for the high coexistence of CVD and COPD is likely to be multifactorial. In general, the increased CVD risk is mostly related to excess adrenergic activity. High sympathetic activity and neurohormonal activity are linked to vascular and myocardial damage, left-ventricular hypertrophy and an increased risk of ischemic episodes [20]. The marked increase in peripheral sympathetic discharge and the increased plasma norepinephrine levels are further increased in the presence of COPD caused by hypoxia. A further increase in the sympathetic discharge may be due to intermittent nocturnal hypoxia in the presence of obstructive sleep apnea or central sleep apnea/Cheyne-Stokes respiration [20]. The progression of CVD in patients with COPD could be further accelerated by a low-grade systemic inflammation which determines coronary atherosclerosis, which ultimately results in ischemic cardiomyopathy.

Autoradiographic and radioligand binding studies have shown the co-existence of both $\beta_{1}$ - and $\beta_{2}$-receptors in the human lung [21], bronchus and trachea [22]. $\beta$ Adrenergic receptors ( $\beta-A R)$ are unevenly distributed throughout the airways, with the highest receptor density in the lung and the lowest in the trachea [23]; receptor distribution and activity are often discrepant; $\beta_{2}$-AR predominate in bronchial smooth muscles, whereas $\beta_{1}$-AR account for 10 and $30 \%$ of $\beta$-receptors in submucosal glands and alveolar walls, respectively. $\beta$-AR (mainly the $\beta_{2}$ subtype) stimulation induces smooth muscle relaxation, clearance of alveolar fluid and changes in ion fluxes.

In the human heart, the $\beta_{1}-\mathrm{AR} / \beta_{2}-\mathrm{AR}$ ratio is about 70-80:30-20\% (about 50-60:50-40\% in HF) [24]; $\beta$-AR activation leads to an increase in the rate and force of myocardial contraction (positive inotropic and chronotropic effects) [24]. Norepinephrine has higher affinity for human cardiac $\beta_{1}$-AR than $\beta_{2}$-AR. In vascular smooth muscles, $\beta_{2}$-AR are predominant and mediate vasodilatation. Their proportion changes depending on both the organ and the disease [25].

$\beta$-AR function is influenced by receptor density and affinity to G-proteins $[23,26]$. In addition, basal signal response is mediated through $\beta$-AR but also through direct activation of adenyl cyclase. $\beta$-AR may exist in mul- 
tiple active conformations, each of which could display a distinct signaling profile, and several polymorphisms of $\beta$-AR have been reported. The former may explain the differences in clinical effectiveness of different $\beta$-blockers and the latter the differences in responses in different patients [27].

Current international guidelines for CHF [12], CAD [28] and hypertension [29] support the benefit of the treatment with $\beta$-blockers in most patients, including COPD patients. Despite this, in selected populations, only $20-70 \%$ of COPD patients with CHF and myocardial infarction (MI) received $\beta$-blockers $[11,18,30-33]$. In the general population, approximately $20 \%$ of COPD patients and $40 \%$ of non-COPD patients were treated with $\beta$-blockers for CHF [11]. The under-use derives from the well-recognized capacity of non-cardioselective $\beta$ blockers to cause bronchoconstriction, which determines a widespread reluctant attitude toward their use in patients such as those suffering from asthma but also COPD [34].

\section{Pharmacology of $\beta$-Blockers}

$\beta$-Blockers are a heterogeneous class of drugs which act by inhibiting the adverse effects of sympathetic nervous system activation. Propranolol was synthesized about 60 years ago and was the prototype of $\beta$-blockers [35]. Since then many compounds have been developed. They are characterized by different pharmacokinetics and pharmacodynamic properties [36-40]. While the older agents have the same effect on $\beta_{1^{-}}$and $\beta_{2}$-receptors, second-generation $\beta$-blockers have a higher affinity for $\beta_{1}$-receptors. Practolol, the first $\beta_{1}$-selective blocker, was introduced in the late 1960s. Subsequently, many other $\beta_{1}$-selective blockers without toxicity were introduced in clinical practice. $\beta_{1}$-Selective blockers have the advantage of a major interaction with cardiac $\beta_{1}$-receptors, and less influence on bronchial tone and vessels. Thus these drugs are rather cardioselective but not cardiospecific. $\beta_{1}$-Receptor selectivity may be a dose-dependent property $[35$, $36]$; consequently, with increasing dose, $\beta_{1}$-selectivity decreases.

Only few $\beta$-blockers can partially activate AR in the absence of endogenous catecholamines, e.g. pindolol and partially acebutolol. They possess a partial agonist activity. In the presence of catecholamines, $\beta$-blockers with intrinsic sympathomimetic activity (ISA), or partial agonist activity $[25,36]$, remain effective anti-hypertensive agents, and cause less slowing of heart rate at rest, less depression of atrioventricular conduction and directly reduce peripheral vascular resistance. However, it is still debated whether $\beta$-blockers with ISA are an advantage or a disadvantage in cardiac therapy $[35,36]$. Some investigators have made claims that ISA in $\beta$-blockers protects against myocardial depression and bronchial constriction. However, evidence supporting the latter claim is unconvincing, since they might potentially cause $\beta_{2}$-AR downregulation [25].

Some $\beta$-blockers, e.g. labetalol and carvedilol, have antagonistic effects on both $\alpha$ - and $\beta$-AR and thus have vasodilating properties $[35,36]$. The $\alpha$-receptor-blocking property determines a reduction in peripheral vascular resistance and a better preservation of cardiac output compared to propranolol. Thus both drugs are useful in treating systemic hypertension and symptomatic congestive HF. Although the function and expression of $\alpha$-receptors in the lung are poorly defined [41], $\alpha$-receptorblocking drugs might have a weak bronchodilating activity.

$\beta$-Blockers exert their activity by preventing agonist binding (neutral antagonists). However, some $\beta$-blockers such as nadolol, carvedilol, bisoprolol and metoprolol also reverse the constitutive activity of unbound $\beta_{2}$-AR in the absence of agonist (inverse agonist). In contrast to $\beta_{2}$-AR agonists which alter $\beta_{2}$-AR such that the affinity for ligands is 10 -fold reduced, with downregulation and desensitization of response, $\beta$-blockers do not provoke desensitization or alterations in receptor conformation. However, chronic long-term administration of $\beta$-blockers causes $\beta$-AR upregulation and increases their density [42]. Consequently, prior exposure to $\beta_{2}$-AR agonists may reduce binding of antagonists to $\beta$-receptors. This may explain the high tolerance for $\beta$-blockers in COPD patients who routinely inhale $\beta_{2}$-AR agonists.

\section{Perioperative Use of $\beta$-Blockers in COPD}

Current guidelines support a relatively wide indication for the perioperative use of $\beta$-blockers in patients undergoing major vascular surgery to reduce the incidence of peri- and postoperative cardiac complications, including sudden death, angina and MI [43]. Indeed, elevated levels of catecholamines during and after surgery are a well-known phenomenon, and in association with hormonal and blood rheology changes and the effects of anesthetics, catecholamines are the mechanisms responsible for cardiovascular complications [44]. 
In a cohort of selected, moderate-to-severe COPD patients, cardioselective $\beta_{1}$-blockers are associated with reduced short- and long-term mortality in patients who underwent major cardiovascular surgery [45]. An overwhelming body of evidence suggests that perioperative $\beta$-AR blockade reduced the occurrence of morbidity related to cardiac complications [46-48], especially in patients at a very high risk of perioperative cardiovascular adverse events [49]. This risk is linked to the preexisting cardiovascular risk factors and to the risk of the procedure itself. The role of $\beta$-blockers in intermediate- and low-risk patients needs to be better defined. Thus the benefit of $\beta$-blocker treatment in COPD patients undergoing major surgery should be determined on an individual basis by balancing the risk/benefit ratio. Finally, their overall impact on patients undergoing non-cardiac surgery has been questioned [50].

\section{$\beta$-Blockers in COPD and MI}

American Heart Association and American College of Cardiology guidelines recommended initiating longterm $\beta$-blocker treatment in all MI patients [28]. The major convincing benefits have been documented in patients with MI, both before and after infarction [51, 52]. The beneficial effects of $\beta$-blockers in patients with COPD who had recently experienced MI have also been demonstrated: survival in patients with and without COPD is similar after MI $[53,54]$. Randomized controlled studies show that mortality was reduced [55] by approximately $15-40 \%$ in COPD patients with coexisting CAD [56]. The effect was similar to that in patients without COPD [55] and possibly limited to patients who have preexisting cardiac disease [53].

\section{$\beta$-Blockers in COPD and Hypertension}

Historically, $\beta$-blockers are a major class of anti-hypertensives. Among COPD patients with hypertension, $\beta$-blockers monotherapy has been shown to reduce allcause mortality compared to other anti-hypertensive drugs [57]. A recent meta-analysis evaluated the efficacy of $\beta$-blockers as first-line therapy for hypertension in preventing major cardiovascular outcomes such as non-fatal MI or stroke, or death. Data from randomized trials [58] showed that several $\beta$-blockers have similar efficacy in patients aged $<60$ years, while in older patients they were associated with a higher risk of cardiovascular events.
Since $\beta$-blockers are not the first-line treatment for hypertension [29], there is no need to use them in COPD patients with hypertension. Thus it could be suggested that $\beta$-blockers must be stopped in these patients and even cardioselective $\beta_{1}$-blockers must be substituted. Indeed, with several classes of drugs available to treat hypertension, the mandatory use of $\beta_{1}$-blockers to treat hypertension in COPD patients became unlikely, with the possible exception of severe hypertension. Although the likelihood of adverse events to all other classes of antihypertensive drugs is extremely low, in this case a trial with a cardioselective $\beta_{1}$-blocker, such as bisoprolol, should be attempted under clinically controlled conditions in COPD patients with hypertension [19].

\section{$\beta$-Blockers in COPD and CHF}

$\beta$-Blockers need to be an integral part of therapy in most patients with CHF [12]. Extensive evidence supports the use of bisoprolol, carvedilol and metoprolol succinate in CHF. They are considered the cornerstone of management of CHF patients with impaired left-ventricular ejection fraction and have been shown to improve HF survival across the entire spectrum of disease severity. The place of $\beta$-blockers in the treatment of diastolic HF is still unclear [59]. The relative risk of mortality is lower in younger patients than in the older patients (aged $>60$ years) or in the very elderly (aged $>75$ years), and the effect is more evident for the non-selective $\beta$-blockers. Available evidence derives from several randomized, prospective clinical trials. It has been shown that a dose-related reduction in mortality is provided by a non-selective $\beta$-blocker such as carvedilol $(-65 \%)$ and by several selective $\beta_{1^{-}}$ blockers such as metoprolol, bisoprolol and nebivolol (approximately $-35 \%$ ), but not by bucindolol. However, the results of these studies could be generalized only to those patients whose characteristics are comparable to those who qualified to participate. It is worth mentioning that the vast majority of randomized clinical trial studying the clinical efficacy of different $\beta$-blockers in patients with CHF excluded COPD patients. When they were included, a selection bias is evident in most HF trials, since only approximately $10 \%$ of patients had COPD whereas the prevalence of COPD is higher in the general population with CHF. Since COPD patients have been frequently excluded from large trials and often treated with a suboptimal dosage, their efficacy in the management of both conditions is somewhat uncertain and still largely based on post hoc analyses of small subgroups. 
Current guidelines recommend the use of $\beta$-blockers in $\mathrm{CHF}$ in the majority of patients with impaired leftventricular ejection fraction [12], even if there is concomitant COPD, but evidence supporting their recommendation is of level $\mathrm{C}$ strength, i.e. based on expert opinion. Although $\beta$-blockers are recommended in all patients with systolic dysfunction, several surveys have shown their consistent under-utilization in COPD, as previously reported. The most cited reasons for non-adherence to clinical guidelines are the potential detrimental side effects of $\beta$-blockade on pulmonary function. In addition, these drugs tend to be administered at a lower-than-recommended dose.

Indeed, restrictive lung disease in patients with severe HF [60] and impaired alveolar gas exchange measured by diffusion for carbon monoxide (DLCO) has been described [61], regardless of COPD [62]. Recently, a doubleblind, placebo-controlled study has shown that bisoprolol given at therapeutic doses for months in patients with stable $\mathrm{HF}$ and moderate-severe COPD significantly reduces $\mathrm{FEV}_{1}$ and DLCO, but not residual volume [63]. However, changes in $\mathrm{FEV}_{1}$ widely varied among patients, were likely to be within the range of long-term variability of this parameter and were of no clinical significance. On the other hand, response to bronchodilator treatment was preserved [63].

\section{$\beta$-Blockers in COPD}

The interaction of $\beta$-blockers with heterogeneous receptors localized in the human airways is not yet well understood. It is known that $\beta$-AR are implicated in the regulation of bronchomotor tone with $90 \%$ of them localized in the alveolar wall of the respiratory system; $70 \%$ of all $\beta$-AR are $\beta_{2}$-AR, whereas $\beta_{1}$-AR account for the remainder. $\beta_{2}$-AR predominate in the bronchial smooth muscles, while $\beta_{1}$-AR are $30 \%$ of $\beta$-AR present in the alveolar wall and $10 \%$ of $\beta$-AR in submucosal glands [21]. Their proportion changes depending on the organ and disease [25]. $\beta_{2}$-AR present in presynaptic position on cholinergic nerves, and stimulation of these $\beta_{2}$-presynaptic AR by $\beta_{2}$-agonists inhibits the release of acetylcholine, a potent bronchoconstrictor [64].

$\beta$-Blockers may induce different pulmonary adverse effects that are relevant to COPD patients. The use of these drugs in COPD has been traditionally contraindicated, mainly for the report of acute bronchoconstriction after their administration [65]. The mechanism that mediates $\beta$-blockade-induced bronchoconstriction in
COPD patients is not entirely known. In patients with asthma, non-selective $\beta$-AR blockade may cause bronchoconstriction by antagonism of inhibitory presynaptic $\beta_{2}$-AR on cholinergic nerves [66] that is associated with an increase in acetylcholine effects on $\mathrm{M}_{2}$ cholinergic receptors. Of note, $\beta$-AR-induced bronchoconstriction does not occur in healthy subjects [67]. Moreover, the airways of healthy subjects are less sensitive to the constricting effect of acetylcholine. Patients with COPD showed an equal or better bronchodilation response to anticholinergic agents than to $\beta_{2}$-agonists $[68,69]$, leading to the hypothesis that non-selective $\beta$-AR blockade causes bronchoconstriction by an unrestricted acetylcholine action [16]. In this case, the heterogeneity of $\mathrm{M}_{2}$ cholinergic receptors in COPD patients may in part explain the variability in the airway response to $\beta$-AR blockade [70].

Alternatively, it could be that the bronchoconstrictor effect of $\beta$-blockers is not directly related to $\beta$-AR blockade $[71,72] . \alpha_{1}$-AR blockade exerts a mild bronchodilator effect on COPD patients and abolishes propranolol-induced bronchoconstriction [73-75]; thus partial or complete $\beta_{2}$-AR blockade with unopposed activation of $\alpha_{1^{-}}$ AR may be responsible for bronchoconstriction induced by non-selective $\beta$-blockers. The $\alpha_{1}$-AR-blocking activity of labetalol and carvedilol may be sufficient to offset $\beta$ AR blockade-induced bronchoconstriction in patients with COPD, but not in asthmatics [45, 76]. The difficulty to assess the exact mechanism of action of $\beta$-blockers has been stressed by the results of a recent study by Baker [26], who for the first time examined receptor affinity of a wide range of $\beta$-blockers using intact cells instead of membrane preparations, and the results are surprising. In fact, this study suggests that many ligands previously considered to have $\beta_{1}$-selectivity, e.g. metoprolol, bisoprolol and atenolol, have a poor $\beta_{1} / \beta_{2}$ selectivity, whereas other $\beta$-blockers prescribed for cardiovascular disease, e.g. carvedilol, sotalol and timolol, have a higher $\beta_{2}$ selectivity. This finding could explain why the effects of metoprolol, a $\beta_{1}$-selective blocker, on bronchial hyperresponsiveness are the same as those of propranolol, a non-selective $\beta$-blocker, in patients with COPD [77]. However, to our knowledge, effectiveness of the drugs in humans depends on more than just receptor affinity. In addition, the pharmacokinetic profile, absorption, metabolism, tissue distribution and elimination of the drug, as well as the longevity of action, are also important. Moreover, there are several different polymorphic variants of $\beta$-AR within the population and this may be associated with differences in drug affinity and action both in the clinical and laboratory setting. 
Cumulative evidence from clinical trials and metaanalyses suggests that selective $\beta_{1}$-blockers in patients with COPD have not significant adverse effects on $\mathrm{FEV}_{1}$, respiratory symptoms or response to $\beta_{2}$-agonists even in patients with advanced disease [78]. However, it should be noted that no long-term study was performed; most studies included few patients and not one study included patients with HF.

Bronchoconstriction may be the consequence of absence of cardioselectivity, since loss of cardioselectivity at high doses and unopposed stimulation of cholinergic muscarinic $\mathrm{M}_{2}$ receptors and $\alpha$-adrenoceptors can impede bronchodilation [16].

Indeed, at least in asthmatics bronchoconstriction induced by $\beta$-blockers is reversed by oxitropium bromide [79] and indoramin and phentolamine [73, 74]. Studies evaluating the effects of $\beta$ - and $\alpha$-blockers in COPD patients are scarce. At normal dosage, labetalol does not affect $\mathrm{FEV}_{1}$ [80] in these patients. On the other hand, nebivolol, a third-generation $\beta$-blocker with highest $\beta_{1^{-}}$ selectivity, results in good tolerability in patients with airway obstruction [81, 82]. Some degree of bronchoconstriction induced by $\beta$-blockers seems to be more frequent in COPD patients with partially reversible airflow obstruction $[16,61,83]$. However, a statistically significant reduction in $\mathrm{FEV}_{1}$ has been found after a 4-month treatment with nebivolol, a $\beta_{1}$-selective blocker, in moderate-severe COPD patients [63]. However, changes were within the range in most patients, and were not associated with changes in residual volume and increased clinical exacerbations [63]. It is remarkable to note that nonselective $\beta$-blockers decreased the bronchodilation response to inhaled $\beta_{2}$-agonists [83], whereas nebivolol, a selective $\beta_{1}$-blocker, did not [63].

A recent, controlled, crossover trial reported that the short-term administration of non-selective $\beta$-blockers increases bronchial hyperresponsiveness in irreversible COPD [77]. It is well known that bronchial hyperresponsiveness is associated with a tendency to a more rapid decline in $\mathrm{FEV}_{1}$ in COPD patients and with increased mortality. However, the long-term effect of $\beta$-blockers was not examined; few patients were studied, some patients treated with placebo show an unexpectedly high bronchial hyperresponsiveness, suggesting selection bias, and mean changes in responsiveness - although significant - were within the range of variability [77]. However, the effect could be time dependent. Long-term administration of carvedilol and nadolol reduced airway hyperresponsiveness in a murine model of asthma; the mechanism of this phenomenon has been suggested to be asso- ciated with the increase in $\beta$-AR density [42]. Recently, these data have been confirmed in humans: a small pilot study demonstrated that the administration of nadolol, which is currently contraindicated in asthmatic patients when chronically administered, shows a beneficial effect on most subjects with mild asthma [84]. The long-term effect of $\beta$-blockers should be more closely addressed.

Finally, $\beta$-blockers may influence gas exchange through a reduction in fluid re-absorption at the level of the alveolar surface [85-87].

Despite these adverse effects, in moderate-severe COPD patients, there is a large safety margin in $\beta$-blocker therapy that is not obvious for asthmatic patients [88]. Thus $\beta_{1}$-selective blockers should not be routinely withheld from cardiac patients with coexistent moderate-severe COPD $[61,78]$.

It remains to be determined if systemic administration of non-selective $\beta$-blockers will have any effect on patients also taking short-acting and/or long-acting $\beta_{2}$-agonists, the mainstay of COPD therapy. Whether chronic administration of $\beta_{2}$-agonists increases the risk for hospitalization and mortality in patients with CHF is still debated [25]. Interestingly enough, a small pilot study indicated that salmeterol use was not associated with any exacerbation of HF [89]. However, it is clear that the issue of safety in long-term treatment with long-acting $\beta_{2}$-agonists in COPD patients with concomitant CHF has not completed been solved yet. As previously discussed, chronic administration of $\beta_{2}$-agonists leads to a 10 -fold reduction in receptor affinity [84], thus reducing the binding of $\beta_{1^{-}}$ blockers to $\beta_{2}$-AR and favoring tolerance with the latter treatment [78]. On the other hand, it appears that chronic administration of $\beta$-blockers could increase $\beta$-AR density, therefore increasing the bronchodilator response of $\beta_{2}$ agonists [37]. Indeed, controlled, prospective studies addressing the issue of concomitant, chronic use of different long-acting $\beta_{2}$-agonists and different $\beta_{1}$-blockers in COPD patients with CVD are lacking.

\section{Principles of $\beta$-Blocker Treatment in COPD}

The decision to begin $\beta$-blocker therapy should be considered on a 'case-by-case basis' in COPD patients and should be left to a specialist. Clinical and perhaps genetic factors should be considered. There is increasing evidence that genetic variation in the $\beta_{1}$-AR locus affects the impact of $\beta$-blockers. It is of interest that the $\beta_{1^{-}}$ Arg389Gly polymorphism consistently appears to predict the efficacy of $\beta$-blockers [27]. 
Close definition of respiratory disease(s), i.e. COPD or COPD plus asthma, is required. Indeed a consistent proportion of patients with respiratory symptoms has been diagnosed with COPD without clear clinical and objective functional evidence. In addition, at least in primary care, the majority of patients with COPD have only mildmoderate airflow obstruction, facilitating cardioselective $\beta$-blocker treatment without an increased risk of unwanted pulmonary effects. Indeed, it is worth mentioning that $\beta$-blockers have never been studied in patients with very severe $\mathrm{COPD}\left(\mathrm{FEV}_{1}<30 \%\right.$ of predicted or $\mathrm{FEV}_{1}$ $<50 \%$ plus chronic respiratory failure) [39].

Cardioselective $\beta_{1}$-blockers (or non-cardioselective $\beta_{1}$-blockers with $\alpha$-blocking activity) should be selected $[35,36]$. Cardioselective $\beta_{1}$-blockers with ISA should be avoided since they might reduce response to $\beta_{2}$-agonists by downregulating $\beta_{2}$-AR [25]. Complete knowledge of the pharmacological properties of each molecule is advisable $[35,36]$. Potential age- and possibly gender-related changes in $\beta$-blocker pharmacokinetics should be considered [38]. In addition, a certain degree of variability in the individual response to $\beta$-blockers might be linked to pharmacogenetics [90].

Only $\beta$-blockers tested in clinical trials (namely carvedilol, long-acting metoprolol and bisoprolol) should be used in asymptomatic or symptomatic LV systolic dysfunction, because their survival benefit has been proven. The cardioselective $\beta_{1}$-blockers metoprolol and bisoprolol have been reported as the first choice for the prevention and treatment of CAD [91].

Thus cardioselective $\beta_{1}$-blockers (without ISA and with a short half-life) should be administered at the lowest dose (such as bisoprolol $1.25 \mathrm{mg}$ daily or nebivolol 1.25 mg daily) in mild-moderate COPD for a minimum period of 1 month before gradual and careful upward titration of the dose to the target range causing a significant $\beta$-blockade over several (8-12) weeks to ensure safety ('start low and go slow') [12]. For instance, the following regime has been proposed for bisoprolol: starting dose $1.25 \mathrm{mg}$ once daily, which is successively increased to 2.5 , $5.0,7.5$ and $10 \mathrm{mg}$ every $2-4$ weeks, according to tolerance [63]. It should be emphasized that such a progressive and individualized method of administration was critical for the transformation of $\beta$-blockers from contraindicated agents in CHF to a critical component of standard management. Moreover, there is a tendency in clinical practice and in non-specialized settings to administer a daily dose which is lower than that in randomized, controlled trials, likely as a consequence of the reluctance of physicians to prescribe the recommended dose. ' $\beta_{1}$-Selective' agents, e.g. bisoprolol, celiprolol and metoprolol, lose selectivity at high doses, becoming effectively non-selective.

Early mild deterioration of pulmonary symptoms after initiation of a $\beta$-blocker may not warrant its prompt discontinuation. Moreover, while titrating the dose, it would be advisable to pretreat patients with an anticholinergic agent such as tiotropium and to use ipratropium or oxitropium bromide for on-demand rescue treatment.

Since even selective $\beta_{1}$-blockers may have different pulmonary effects, their use in at-risk COPD patients should be always guided by the combination of lung function evaluation $\left(\mathrm{FEV}_{1}\right.$ for airflow obstruction and residual volume for hyperinflation) and assessment of DLCO. The latter measurement is recommended when HF comorbidity is present $[92,93]$.

Prediction of a detrimental effect of $\beta$-blockers on lung function in COPD patients has been based on the presence of a significant acute bronchodilator response to $\beta_{2^{-}}$ adrenergic agonists and anticholinergic agents [19] and/or on the presence of methacholine responsiveness [94]. Neither method is however satisfactory. Indeed, under carefully controlled conditions up to 50\% of COPD patients demonstrate a significant response to bronchodilators [95], thus limiting the utility of this method. Most but not all guidelines for CVD suggest that the presence of reversibility of obstruction should be measured in COPD patients before introducing $\beta$-blockers. However, a large European trial performed in the primary-care setting showed that few patients performed baseline pulmonary function tests despite the fact that most patients were on bronchodilator treatment [33]. In addition, the presence of methacholine responsiveness in COPD has been regarded as an index of the presence of 'an asthmatic component'. These patients should be at risk of a greater bronchoconstrictive response to $\beta$-blockers. However, a large proportion of COPD patients (up to 70\%) may also show bronchial hyperresponsiveness [96]. Alternatively, methacholine responsiveness has been measured during short-term treatment with $\beta$-blockers [77]. Indeed, methacholine response increased more following the administration of non-selective $\beta$-blockers. The long-term effect has never been studied, but at variance it could be beneficial $[42,83]$. However, such a method cannot be used in patients with moderate-severe obstruction [97] and is highly influenced by the degree of airflow obstruction. It remains a research tool rather than a clinical practice protocol. Perhaps genotype testing for $\beta_{2}$-AR would prove to be useful in the future to detect patients at risk of developing a more severe bronchoconstrictive response. 
Additional factors should be considered in case of suboptimal results. There is widespread recognition of patient-to-patient variability in drug response. Pharmacogenetic studies will help to determine the response of individual patients to $\beta$-blockers [90]. Up to now, physicians cannot anticipate who of their patients will benefit most or at all. Consistent systemic inflammation associated with COPD may accelerate the metabolism of $\beta$-blockers, leading to reduced efficacy. Evidence indicates that females may demonstrate a greater response to $\beta$-blockers. However, data in female patients are very limited and results from males may not be simply extrapolated to females. Much uncertainty exists regarding the tolerability and relative efficacy of $\beta$-blockers regardless of age. Thus doubts remain about their advisability in the elderly. However, the blood pressure-lowering effect of $\beta$-blockers is more marked in the elderly than in younger patients, and thus they may require a lower dose.

\section{Conclusion}

At present, data on the safety of selective $\beta_{1}$-blockers in patients with COPD were derived from studies that generally included small groups of poorly characterized patients with treatments given for a short period of time. Indeed, there are still several questions that need to be addressed. However, the well-proven efficacy of $\beta$-blockers on survival in several high-risk CVD patients, including CHF, should prompt their use in the large proportion of COPD patients who had such co-morbidities. Since absolute contraindications are difficult to predict apart from overt history of bronchial asthma, it is not logical to abandon the use of selective $\beta_{1}$-blockers in the presence of a diagnosis of COPD $[12,83]$ or possibly in the presence of severe disease, too [12]. $\beta_{1}$-Blockers should be carefully selected not only on the basis of cardioselectivity and proven efficacy on mortality, but also with respect to the challenging deleterious effects on respiratory symptoms, lung function and gas exchange in individual patients. In addition, the dosage of selective $\beta_{1}$-blockers should be progressively titrated on a case-by-case basis with regular monitoring over a period of several weeks since observational studies suggest that the mean daily dose could be half of the target dose recommended in randomized controlled studies.

Although the benefits of chronic treatment with selective $\beta_{1}$-blockers may far outweigh the risks of induced bronchoconstriction [12], the use of $\beta$-blockers is seriously inadequate since the diagnosis of COPD per se is still a barrier or is perceived as a serious contraindication by many physicians, particularly in case of potential pulmonary sequelae. Thus their erratic use is a direct consequence of reluctance and prejudice [34]. It has been estimated that the reluctance to use $\beta$-blockers in patients with $\mathrm{CHF}$ according to current guidelines contributes to approximately 7,800 deaths per year in the UK, a significant proportion of them being patients with both CHF and COPD [98]. Both primary- and secondary-care physicians need greater support in managing COPD patients requiring selective $\beta_{1}$-blockers. Ultimately only changing the prejudice will solve the dilemma of the optimal use of $\beta$-blockers in COPD.

As pneumologists we can no longer tolerate that only $30 \%$ patients with COPD and CHF have confirmatory spirometry and echocardiography to substantiate the diagnosis, while in $50 \%$ of them only echocardiogram was performed [99]. As physicians, we can no longer tolerate that $>50 \%$ of patients with HF without COPD are treated with $\beta$-blockers compared to only $20 \%$ of patients with $\mathrm{HF}$ and COPD $[11,100]$, and that on average the daily dosage of $\beta$-blockers remains far below the target doses [100], strongly suggesting that clinicians often fail to perform a substantial dose-ranging study, and that $\beta$-blockers for which no substantial trial in HF exists are prescribed in $10-20 \%$ of patients with HF and systolic dysfunction $[98,100]$.

The importance of including $\beta$-blockers, a pivotal treatment modifying and prolonging life, in the standard treatment of most COPD patients with coexisting CVD should be supported by a detailed, critical analysis of the large body of scientific evidence that demonstrates the life-saving efficacy and safety of the long-term treatment with $\beta$-blockers. Additionally, we should call for results of long-term, prospective, clinical trials fully addressing the impact of this fundamental treatment in patients with COPD complicated by CVD in the real world. Meanwhile, pneumologists and cardiologists should develop a detailed and standardized protocol for individual COPD patients based on current knowledge and on wide testing of pulmonary function to guide and enhance the safe use of selective $\beta_{1}$-blockers in everyday practice, which could significantly reduce the physicians' mistrust of $\beta$-blockers in COPD patients. Hopefully, we are at the beginning of a new era in which the use of $\beta$-blockers would be characterized by a detailed clinical evaluation, pathophysiological measurements, and knowledge of the pharmacological properties of each molecule and its pharmacokinetic and pharmacodynamic parameters in different populations, and efficacy being predicted by pharmacogenomics. 


\section{References}

$\checkmark 1$ Murray CJ, Lopez AD: Alternative projections of mortality and disability by cause 1990-2020: Global Burden of Disease Study. Lancet 1997;349:1498-1504.

-2 Cazzola M, Bettoncelli G, Sessa E, Cricelli C, Biscione G: Prevalence of comorbidities in patients with chronic obstructive pulmonary disease. Respiration 2010;80:112-119.

>3 Kuller LH, Ockene JK, Townsend M, Browner W, Meilahn E, Wentworth DN: The epidemiology of pulmonary function and COPD mortality in the multiple risk factor intervention trial. Am Rev Respir Dis 1989; 140:S76-S81.

$\checkmark 4$ Sin DD, Anthonisen RR, Soriano JB, Agusti AG: Mortality in COPD: role of comorbidities. Eur Respir J 2006;28:1245-1257.

$\checkmark 5$ McGarvey LP, John M, Anderson JA, Zvarich $\mathrm{M}$, Wise RA: Ascertainment of causespecific mortality in COPD: operations of the TORCH Clinical Endpoint Committee. Thorax 2007;62:411-415

6 Curkendall SM, DeLuise C, Jones JK, Lanes S, Stang MR, Goehring EJ, She D: Cardiovascular disease in patients with chronic obstructive pulmonary disease, Saskatchewan Canada cardiovascular disease in COPD patients. Ann Epidemiol 2006;16:63-70.

$\checkmark 7$ Macchia A, Monte S, Romero M, D’Ettorre A, Tognoni G: The prognostic influence of chronic obstructive pulmonary disease in patients hospitalised for chronic heart failure. Eur J Heart Fail 2007;9:942-948.

$\checkmark 8$ Rutten FH, Cramer MJ, Lammers JW, Grobbee DE, Hoes AW: Heart failure and chronic obstructive pulmonary disease: an ignored combination? Eur J Heart Fail 2006;8:706711.

9 Havranek EP, Masoudi FA, Westfall KA, Wolfe P, Ordin DL, Krumholz HM: Spectrum of heart failure in older patients: results from the National Heart Failure project. Am Heart J 2002;143:412-417.

-10 Hawkins NM, Petrie MC, Jhund PS, Chalmers GW, Dunn FG, McMurray JJ: Heart failure and chronic obstructive pulmonary disease: diagnostic pitfalls and epidemiology. Eur J Heart Fail 2009;11:130-139.

-11 Hawkins NM, Jhund PS, Simpson CR, Petrie MC, MacDonald MR, Dunn FG, MacIntyre K, McMurray JJV: Primary care burden and treatment of patients with heart failure and chronic obstructive pulmonary disease in Scotland. Eur J Heart Fail 2010;12:1-8.

$>12$ Task Force for Diagnosis and Treatment of Acute and Chronic Heart Failure 2008 of European Society of Cardiology, Dickstein K, Cohen-Solal A, Filippatos G, McMurray JJ, Ponikowski P, Poole-Wilson PA, Stromberg A, van Veldhuisen DJ, Atar D, Hoes AW, Keren A, Mebazaa A, Nieminen M, Priori SG, Swedberg K, Vahanian A, Camm J, De Caterina R, Dean V, Funck-Brentano C, Hellemans I, Kristensen SD, McGregor K, Sechtem U, Silber S, Tendera M, Widimsky P,
Zamorano JL: ESC Guidelines for the diagnosis and treatment of acute and chronic heart failure 2008: the Task Force for the Diagnosis and Treatment of Acute and Chronic Heart Failure 2008 of the European Society of Cardiology. Developed in collaboration with the Heart Failure Association of the ESC (HFA) and endorsed by the European Society of Intensive Care Medicine (ESICM). Eur Heart J 2008;29:2388-2442.

13 Boudestein LCM, Rutten FH, Cramer MJ, Lammers JW, Hoes AW: The impact of concurrent heart failure on prognosis in patients with chronic obstructive pulmonary disease. Eur J Heart Fail 2009;11:1182-1188.

14 Huiart L, Ernst P, Suissa S: Cardiovascular morbidity and mortality in COPD. Chest 2005;128:2640-2646.

15 Lainscak M, Hodoscek LM, Düngen HD, Rauchhaus M, Doehner W, Anker SD, von Haehling S: The burden of chronic obstructive pulmonary disease in patients hospitalized with heart failure. Wien Klin Wochenschr 2009;121:309-313.

16 Sirak TE, Jelic S, Le Jemtel TH: Therapeutic update: non-selective beta- and alpha-adrenergic blockade in patients with coexistent chronic obstructive pulmonary disease and chronic heart failure. J Am Coll Cardiol 2004;44:497-502.

17 Antonelli Incalzi R, Fuso L, De Rosa M, Forastiere F, Rapiti E, Nardacchia B, Pistelli R: Comorbidity contributes to predict mortality of patients with chronic obstructive pulmonary disease. Eur Respir J 1997;10:2794-2800.

- 18 Egred M, Shaw S, Mohammad B, Waitt P, Rodrigues E: Under-use of beta-blockers in patients with ischaemic heart disease and concomitant chronic obstructive pulmonary disease. QJM 2005;98:493-497.

19 Dart RA, Gollub S, Lazar J, Nair C, Schroeder D, Wolf SH: Treatment of systemic hypertension in patients with pulmonary disease: COPD and asthma. Chest 2003;123: 222-243.

20 Floras JS: Sympathetic nervous system activation in human heart failure. Clinical implications of an updated model. J Am Coll Cardiol 2009;54:375-385.

21 Carstairs JR, Nimmo AJ, Barnes PJ: Autoradiographic visualization of beta adrenoceptor subtypes in human lung. Am Rev Respir Dis 1985;132:541-547.

-22 van Koppen CJ, Hermanussen MW, Verrijp KN, Rodrigues de Miranda JF, Beld AJ, Lammers JW, van Ginneken CA: $\beta$-Adrenoceptors in human tracheal smooth muscle: characteristics of binding and relaxation. Life Sci 1987;40:2561-2570.

23 Abraham G, Kottkea C, Dheinb S, Ungemacha FR: Pharmacological and biochemical characterization of the beta-adrenergic signal transduction pathway in different segments of the respiratory tract. Biochem Pharmacol 2003;66:1067-1081.
24 Brodde OE: $\beta_{1}$ - and $\beta_{2}$-adrenoceptors in the human heart: properties, function and alterations in chronic heart failure. Pharmacol Rev 1991;43:203-242.

25 Matera MG, Martuscelli E, Cazzola M: Pharmacological modulation of $\beta$-adrenoceptor function in patients with coexisting chronic obstructive pulmonary disease and chronic heart failure. Pulm Pharmacol Ther 2010;23: $1-8$.

26 Baker JG: The selectivity of b-adrenoceptor antagonists at the human $\beta_{1}, \beta_{2}$ and $\beta_{3}$ adrenoceptors. Br J Pharmacol 2005; 144:317-322.

-27 Molenaar P, Chen L, Semmler ABT, Parsonage WA, Kaumann AJ: Human heart $\beta$-adrenoceptors: $\beta_{1}$-adrenoceptor diversification through affinity states and polymorphism. Clin Exp Pharmacol Physiol 2007;34:1020-1028.

28 Smith SC Jr, Allen J, Blair SN, Bonow RO, Brass LM, Fonarow GC, Grundy SM, Hiratzka L, Jones D, Krumholz HM, Mosca L, Pasternak RC, Pearson T, Pfeffer MA, Taubert KA; AHA/ACC, National Heart Lung and Blood Institute: AHA/ACC guidelines for secondary prevention for patients with coronary and other atherosclerotic vascular disease: 2006 update: endorsed by the National Heart, Lung, and Blood Institute. Circulation 2006;113:2363-2372.

29 Mancia G, De Backer G, Dominiczak A, Cifkova R, Fagard R, Germano G, Grassi G, Heagerty AM, Kjeldsen SE, Laurent S, Narkiewicz K, Ruilope L, Rynkiewicz A, Schmieder RE, Struijker Boudier HA, Zanchetti A: 2007 guidelines for the management of arterial hypertension. The Task Force for the Management of Arterial Hypertension of the European Society of Hypertension (ESH) and of the European Society of Cardiology (ESC). J Hypertens 2007;25:1105-1187.

30 Dransfield MT, Rowe SM, Johnson JE, Bailey WC, Gerald LB: Use of beta blockers and the risk of death in hospitalised patients with acute exacerbations of COPD. Thorax 2008; 63:301-305.

31 Simpson E, Beck C, Richard H, Eisenberg MJ, Pilote L: Drug prescriptions after acute myocardial infarction: dosage, compliance, and persistence. Am Heart J 2003;145:438-444.

32 Bradford WD, Chen J, Krumholz HM: Under-utilisation of beta-blockers after acute myocardial infarction. Pharmacoeconomic implications. Pharmacoeconomics 1999;15: 257-268.

33 Cleland JG, Cohen-Solal A, Aguila JC, Dietz R, Follath F, Freemantle N, Gavazzi A, van Gilst GW, Hobbs FD, Korewicki J, Madeira HC, Preda I, Swedberg K, Widimsky J, IMPROVEMENT of Heart Failure Programme Committees and Investigators: Management of heart failure in primary care (the IMPROVEMENT of Heart Failure Programme): an international survey. Lancet 2002;360: 1631-1639. 
34 Erdmann E: Safety and tolerability of betablockers: prejudices and reality. Eur Heart J 2009;11(suppl A):A21-A25.

35 Frishman WH: $\beta$-Adrenergic blockers: a 50year historical perspective. Am J Ther 2008; 15:565-576.

-36 Reiter MJ: Cardiovascular drug class specificity: beta-blockers. Prog Cardiovasc Dis 2004;47:11-33

37 Ashrfian H, Violaris AG: Beta-blocker therapy of cardiovascular diseases in patients with bronchial asthma or COPD: the pro viewpoint. Prim Care Respir 2005;14:236241

38 Coats AJ: Beta-adrenoceptor antagonists in elderly patients with chronic heart failure: therapeutic potential of third-generation agents. Drugs Aging 2006;23:93-99.

- 39 Antonelli Incalzi R, Pedone C: Respiratory effects of $\beta$-adrenergic receptor blockers. Curr Med Chem 2007;14:1121-1128.

-40 Andrus MR, Loyed JV: Use of $\beta$-adrenoceptor antagonists in older patients with chronic obstructive pulmonary disease and cardiovascular co-morbidity: safety issues. Drugs Aging 2008;25:131-144.

41 Novakova M, Myslivecek J: Identification of all $\alpha_{1}$-adrenoceptor subtypes in rat lung. Gen Physiol Biophys 2005;25:349-353.

-42 Callaerts-Vegh Z, Evans KL, Dudekula N, Cuba D, Knoll BJ, Callaerts PF, Giles H, Shardonofsky FR, Bond RA: Effects of acute and chronic administration of beta-adrenoceptor ligands on airway function in a murine model of asthma. Proc Natl Acad Sci USA 2004;101:4948-4953.

-43 Fleischmann KE, Beckman JA, Buller CE, Calkins H, Fleisher LA, Freeman WK, Froehlich JB, Kasper EK, Kersten JR, Robb JF, Valentine RJ: 2009 ACCF/AHA focused update on perioperative beta blockade. J Am Coll Cardiol 2009;54:2102-2128.

-44 Selzman CH, Miller SA, Zimmerman MA, Harken AH: The case for beta-adrenergic blockade as prophylaxis against perioperative cardiovascular morbidity and mortality. Arch Surg 2001;136:286-290.

-45 Van Gestel Y, Hocks SE, Sin DD, Schouten O, Witteven HJ, Simsek C, Stam H, Mertens FW, Bax JJ, van Domburg RT, Poldermans D: Impact of cardioselective beta-blockers on mortality in patients with chronic obstructive pulmonary disease and atherosclerosis. Am J Respir Crit Care Med 2008;178:695700 .

46 Rajeev S, Wong DT: Effect of beta-blockers on perioperative myocardial ischemia in patients undergoing noncardiac surgery. Curr Drug Targets 2009;10:833-841.

-47 Schouten O, Shaw LJ, Boersma E, Bax JJ, Kertai MD, Feringa HH, Biagini E, Kok NF, Urk $\mathrm{H}$, Elhendy A, Poldermans D: A meta-analysis of safety and effectiveness of perioperative beta-blocker use for the prevention of cardiac events in different types of noncardiac surgery. Coron Artery Dis 2006;17:173179 .
48 McGory ML, Maggard MA, Ko CY: A metaanalysis of perioperative beta blockade: what is the actual risk reduction? Surgery 2005; 138:171-179.

49 Domanski D, Schwarz ER: Is the perioperative use of $\beta$-blockers still recommended? A critical review of recent controversies. J Cardiovasc Pharmacol Ther 2009;14:258-268.

50 Talati R, Reinhart KM, White CM, Pungh OJ, Sedrakyan A, Kluger J, Coleman CJ: Outcomes of perioperative beta-blockade in patients undergoing noncardiac surgery: a meta-analysis. Ann Pharmacother 2009;43: 1181-1188.

- 51 Freemantle N, Cleland J, Young P, Mason J, Harrison J: $\beta$ Blockade after myocardial infarction: systematic review and meta regression analysis. BMJ 1999;318:1730-1737.

52 Gheorghiade M, Goldstein S: Beta blockers in the post myocardial infarction patient. Circulation 2002;106:394-398.

53 Gottlieb SS, McCarter RJ, Vogel RA: Effect of beta-blockade on mortality among highrisk and low-risk patients after myocardial infarction. N Engl J Med 1998;339:489-497.

54 Chen J, Radford MJ, Wang Y, Marciniak TA, Krumholz HM: Effectiveness of beta-blocker therapy after acute myocardial infarction in elderly patients with chronic obstructive pulmonary disease or asthma. J Am Coll Cardiol 2001;37:1950-1956.

55 Hawkins NM, Huang Z, Pieper KS, Solomon SD, Kober L, Velazquez EJ, Swedberg K, Pfeffer MA, McMurray JJV, Maggioni AP: Chronic obstructive pulmonary disease is an independent predictor of death but not atherosclerotic events in patients with myocardial infarction: analysis of the Valsartan in Acute Myocardial Infarction Trial (VALIANT). Eur J Heart Fail 2009;11:292-298.

56 Andrus MR, Holloway KP, Clark DB: Use of beta-blockers in patients with COPD. Ann Pharmacother 2004;38:142-145.

$57 \mathrm{Au} \mathrm{DH}$, Bryson CL, Fan VS, Udris EM, Curtis JR, McDonell MB, Fihn SD: Beta-blockers as single-agent therapy for hypertension and the risk of mortality among patients with chronic obstructive pulmonary disease. Am J Med 2004;117:925-931.

58 Wiysonge CS, Bradley $\mathrm{H}$, Mayosi BM, Maroney $\mathrm{R}$, Mbewu A, Opie LH, Volmink L: Beta-blockers for hypertension. Cochrane Database Syst Rev 2007;1:CD002003.

59 Hogg K, McMurray J: The treatment of heart failure with preserved ejection fraction ('diastolic heart failure'). Heart Fail Rev 2006;11: $141-146$.

60 Wasserman K, Zhang YY, Gitt A, Belardinelli R, Koike A, Lubarsky L, Agostoni PG: Lung function and exercise gas exchange in chronic heart failure. Circulation 1997;96:22212227.
61 Kotlyar E, Keogh AM, MacDonald PS, Arnold RH, McCaffrey DJ, Glanville AR: Tolerability of carvedilol in patients with heart failure and concomitant chronic obstructive pulmonary disease or asthma. J Heart Lung Transplant 2002;21:1290-1295.

62 Agostoni P, Bussotti M, Cattadori G, Margutti E, Contini M, Muratori M, Marenzi G, Fiorentini C: Gas diffusion and alveolar-capillary unit in chronic heart failure. Eur Heart J 2006; 27:2538-2543.

63 Hawkins NM, MacDonald MR, Petrie MC, Chalmers GW, Carter R, Dunn FG, McMurray JJV: Bisoprolol in patients with heart failure and moderate to severe chronic obstructive pulmonary disease: a randomized controlled trial. Eur J Heart Fail 2009;11: 684-690.

64 Ind PW: Catecholamines; in Barnes PJ, Grunstein MM, Leff AR, Woolcock AJ (eds): Asthma. Philadelphia, Lippincott-Raven, 1997, pp 977-1008

65 Cazzola M, Noschese P, Matera MG: The pharmacologic treatment of uncomplicated arterial hypertension in patients with airway dysfunction. Chest 2002;121:230-241.

-66 Boushey HA, Holtzman MJ, Sheller JR, Nadel JA: Bronchial hyperreactivity. Am Rev Respir Dis 1980;121:389-413.

67 Chetta A, Foresi A, Garavaldi G, Corbo GM, Olivieri D: Evaluation of bronchial responsiveness by pharmacological challenges in asthma: inhaled propranolol in comparison with histamine and methacholine. Respiration 1988;54(suppl 1):184-189.

68 Gross NJ, Skorodin MS: Role of the parasympathetic system in airway obstruction due to emphysema. N Engl J Med 1984;311:421425 .

-69 Rebuck AS, Chapman KR, Abboud R, Pare PD, Kreisman H, Wolkove N, Vickerson F: Nebulized anticholinergic and sympathomimetic treatment of asthma and chronic obstructive airways disease in the emergency room. Am J Med 1987;82:59-64.

70 On LS, Boonyongsunchai P, Webb S, Davies L, Davies L, Calverley PM, Costello RW: Function of pulmonary neuronal $\mathrm{M}_{2}$ muscarinic receptors in stable chronic obstructive pulmonary disease. Am J Respir Crit Care Med 2001;163:1320-1325.

71 Godfrey S, Konig P: Inhibition of exerciseinduced asthma by different pharmacological pathways. Thorax 1976;31:137-143.

72 Ney UM: Propranolol-induced airway hyperreactivity in guinea-pigs. Br J Pharmacol 1983;79:1003-1010.

73 Van Mieghem W, Stevens E, Billiet L: Phentolamine therapy in severe chronic asthmatiform bronchitis. Respiration 1981;42:184187.

74 Black JL, Temple DM, Anderson SD: Longterm trial of an alpha-1 adrenoceptor blocking drug (Indoramin) in asthma: a preliminary report. Scand J Respir Dis 1978;59: 307-312. 
75 Mathe AA, Astrom A, Persson NA: Some bronchoconstricting and bronchodilating responses of human isolated bronchi: evidence for the existence of alpha-adrenoceptors. J Pharm Pharmacol 1971;23:905-910.

76 van Zwieten PA: Pharmacodynamic profile of carvedilol. Cardiology 1993;82(suppl): 19-23.

-77 van der Woude HJ, Zaagsma J, Postma DS, Aalbers R, van Hulst M: Detrimental effects of $\beta$-blockers in COPD: a concern for nonselective $\beta$-blockers. Chest 2005;127:818-824.

78 Salpeter S, Omiston T, Salpeter E: Cardioselective beta-blockers for chronic obstructive pulmonary disease. Cochrane Database Syst Rev 2005;4:CD003566.

79 Ind PW, Dixon CM, Fuller RW, Barnes PJ: Anticholinergic blockade of beta-blockerinduced bronchoconstriction. Am Rev Respir Dis 1989;139:1390-1394.

-80 George RB, Manocha K, Burford JG, Conrad SA, Kinasewitz GT: Effects of labetalol in hypertensive patients with chronic obstructive pulmonary disease. Chest 1983;83:457-460.

>81 Münzel T, Gori T: Nebivolol: the somewhatdifferent beta-adrenergic receptor blocker. J Am Coll Cardiol 2009;54:1491-1499.

-82 Dal Negro R: Pulmonary effects of nebivolol. Ther Adv Cardiovasc Dis 2009;3:329-334

$\checkmark 83$ Le Jemtel TH, Padeletti M, Jelic S: Diagnostic and therapeutic challenges in patients with coexistent chronic obstructive pulmonary disease and chronic heart failure. J Am Coll Cardiol 2007;49:171-180.

>84 Hanania NA, Singh S, El-Wali R, Flashner M, Franklin AE, Garner WJ, Dickey BF, Parra S, Ruoss S, Shardonofsky F, O'Connor BJ, Page C, Bond RA: The safety and effects of the beta-blocker, nadolol, in mild asthma: an open-label pilot study. Pulm Pharmacol Ther 2008;21:134-141.
85 Mutlu GM, Koch WJ, Factor P: Alveolar epithelial $\beta_{2}$-adrenergic receptors. Their role in regulation of alveolar active sodium transport. Am J Respir Crit Care Med 2004;170: 1270-1275.

86 Puri S, Dutka DP, Baker BL, Hughes JMB, Cleland JGF: Acute saline infusion reduces alveolar-capillary membrane conductance and increases airflow obstruction in patients with left ventricular dysfunction. Circulation 1999;99:1190-1196.

87 Crone C, Saumon G, Basset G: News from the alveoli. News Physiol 1990;5:50-53.

88 Brooks TW, Creekmore FM, Young DC, Asche CV, Samuelson WM: Rates of hospitalizations and emergency department visits in patients with asthma and chronic obstructive pulmonary disease taking betablockers. Pharmacotherapy 2007;27:684690.

89 Ng TM, Munger MA, Lombardi WL, Doing TH, Ryujin DT, Young DC, Lugo RA: Chronically inhaled salmeterol improves pulmonary function in heart failure. J Cardiovasc Pharmacol 2002;40:140-145.

90 Azuma J, Nonen S: Chronic heart failure: $\beta$ blockers and pharmacogenetics. Eur J Clin Pharmacol 2009;65:3-17.

-91 Camsari A, Arikan S, Avan C, Kaya D, Pekdemir H, Ciçek D, Kiykim A, Sezer K, Akkuş N, Alkan M, Aydoğdu S: Metoprolol, a $\beta$-1 selective blocker, can be used safely in coronary artery disease patients with chronic obstructive pulmonary disease. Heart Vessels 2003;18:188-192.

92 Agostoni P, Contini M, Apostolo A, Sciomer S, Palermo P, Fiorentini P: Lung function with carvedilol and bisoprolol in chronic heart failure: is $\beta$-selectivity relevant? Eur J Heart Fail 2007;9:827-833.

$>93$ Agostoni P, Palermo P, Contini M: Respiratory effects of beta-blocker therapy in heart failure. Cardiovasc Drugs Ther 2009;23:377384.

94 Popio KA, Jackson DH Jr, Utell MJ, Swinburne AJ, Hyde RW: Inhalation challenge with carbachol and isoproterenol to predict bronchospastic response to propranolol in COPD. Chest 1983;83:175-179.
95 Tashkin DP, Celli B, Senn S, Burkhart D, Kesten S, Menjoge S, Decramer M, UPLIFT Study Investigators: A 4-year trial of tiotropium in chronic obstructive pulmonary disease. N Engl J Med 2008;359:1543-1554.

96 Woolcock AJ, Anderson SD, Peat JK, Du Toit JI, Zhang YG, Smith CM, Salome CM: Characteristics of bronchial hyperresponsiveness in chronic obstructive pulmonary disease and in asthma. Am Rev Respir Dis 1991;143: 1438-1443.

-97 Sterk PJ, Fabbri LM, Quanjer PH, Cockcroft DW, O’Byrne PM, Anderson SD, Juniper EF, Malo JL: Airway responsiveness: standardized challenge testing with pharmacological, physical and sensitizing stimuli in adults. Report Working Party Standardization of Lung Function Tests, European Community for Steel and Coal: Official Statement of the European Respiratory Society. Eur Respir J Suppl 1993;16:53-83.

98 Shah SM, Carey IM, DeWilde S, Richards N, Cook DG: Trends and inequities in betablocker prescribing for heart failure. Br J Gen Pract 2008;58:862-869.

99 Damarla M, Celli BR, Mullerova HX, PintoPlata VM: Discrepancy in the use of confirmatory tests in patients hospitalized with the diagnosis of chronic obstructive pulmonary disease or congestive heart failure. Respir Care 2006;51:1120-1124.

100 Komajda M, Follath F, Swedberg K, Cleland J, Aguilar JC, Cohen-Solal A, Dietz R, Gavazzi $A$, van Gilst WH, Hobbs $\mathrm{R}$, Korewicki J, Madeira HC, Moiseyev VS, Preda I, Widimsky J, Freemantle N, Eastaugh J, Mason J, Study Group on Diagnosis of the Working Group on Heart Failure of the European Society of Cardiology: The EuroHeart Failure Survey programme - a survey on the quality of care among patients with heart failure in Europe. Part 2: treatment. Eur Heart J 2003;24:464-474. 